Case Report

\title{
Paraneoplastic Syndrome in Splenic Marginal Zone Lymphoma: A Rare Phenomenon of Paraplegia as an Atypical Presenting Manifestation
}

\author{
Jessica Schering and Vijayalakshmi Donthireddy \\ Hematology/Oncology Department, Henry Ford Hospital, Detroit, MI 48202, USA \\ Correspondence should be addressed to Jessica Schering; jscheril@hfhs.org
}

Received 5 January 2016; Revised 15 March 2016; Accepted 28 March 2016

Academic Editor: Marie-Christine Kyrtsonis

Copyright (C) 2016 J. Schering and V. Donthireddy. This is an open access article distributed under the Creative Commons Attribution License, which permits unrestricted use, distribution, and reproduction in any medium, provided the original work is properly cited.

We describe a case presenting complaint of complete lower body paraparesis, which was discovered to have splenic marginal zone lymphoma (SMZL). While paraneoplastic syndromes are more common in tumors, such as small cell lung cancer, very few reports exist on this condition with SMZL. We describe such a rare entity with a clinical course spanning twenty-four months after diagnosis.

\section{Introduction}

Splenic marginal zone lymphoma (SMZL) is a rare disease, originating from mature B-lymphocytes that are normally present in the marginal zone of lymphoid follicles found in the lymph nodes, spleen, and mucosal lymphoid tissues [1]. Classified as an indolent lymphoma, it accounts for less than one percent of all NHLs [2].

Presenting clinical features of SMZL include splenomegaly, lymphocytosis, or cytopenias. Unlike other NHLs, lymphadenopathy and involvement of extralymphatic organs are uncommon. Splenic pathologic examination can show follicles with expanded mantle and marginal zones and areas of coalescence [3]. The immunophenotype is characterized by expression of CD20 but lack of CD5 or CD10, which is useful in distinguishing this disease from other indolent lymphomas [4].

Splenectomy was considered the optimal first-line therapy in symptomatic patients. Splenectomy alone can achieve an ORR of $80-90 \%[5,6]$. With the addition of chemotherapy to splenectomy, complete response rates can be improved, though historically known to be with moderate activity [7]. Rituximab alone or in combination (e.g., bendamustine) has been shown to be effective with overall response rates greater than $90 \%$, with almost half of responses being complete, while the 5-year progression-free survival is approximately $70 \%$ [812].

Prognosis is generally good with median overall survival of 10 years, though some have a more aggressive course.

\section{Case Presentation}

We present a case of a 64-year-old Caucasian female with no significant medical history, presenting with an ascending bilateral lower extremity weakness and numbness and tingling that started a month prior. She complained of worsening weakness leading to paraplegia with night sweats present for a week prior to presentation. Initial lab work revealed a hemoglobin level of $10.6 \mathrm{~g} / \mathrm{dL}$ and platelet count of $136 \mathrm{~K} / \mu \mathrm{L}$. Her WBCs were within normal range, although with increased absolute lymphocytes and monocytes.

Initial examination showed 3/5 strength of hip flexors, $4 / 5$ knee flexors, and $5 / 5$ plantar flexors. During inpatient course, neurologic status worsened to a strength of $1 / 5$ in hip flexors and $0 / 5$ strength bilaterally of hip extensors, abductors, adductors, knee flexors, extensors, ankle dorsiflexors, plantar flexors, foot inverters, evertors, toe extensors, and flexors. Her reflexes were $2 / 4$ in the biceps, triceps, and brachioradialis, and the knees bilaterally, however, were $0 / 4$ in the bilateral ankles. A positive Babinski sign was noted bilaterally. 
MRI of the brain and complete spine did not disclose any infiltrative process, though diffuse hypointensity within the visualized cervical and thoracic spine was suspicious for diffuse bone marrow replacement process. Electromyography showed mild sensorimotor peripheral neuropathy. Bloodwork showed normal copper levels and paraneoplastic profile (ANNA-1,-2, and -3; AGNA, PCA 1,2, and Tr; Amphiphysin, CRMP-5). Viral studies including HTLV-2, ENA, ACE, and PRP were negative. HIV ELISA was reactive, although western blot was negative. HepBsAg was positive while HepB DNA was negative. IgM cryoglobulins were elevated at $2.0 \mathrm{mg} / \mathrm{dL}$. CSF analysis showed $12 \mathrm{WBCs}$ and lymphocytic pleocytosis with oligoclonal bands. West Nile Virus IgG antibodies were positive, though IgM antibodies were negative. Due to suspicion of Guillain-Barré syndrome, she was initiated on plasmapheresis. She received five treatments with no improvement of her presenting symptoms.

Initial workup for her anemia showed normal iron indices, B12, and folate levels. Rheumatoid factor and ANA were negative. JAK-2 mutation was not present. Reticulocytes were at $1.9 \%$. Bone marrow biopsy was performed. Microscopic evaluation revealed $80 \%$ replacement of her marrow with mature B-cell lymphoma (Image 1 in Supplementary Material available online at http://dx.doi.org/10.1155/2016/ 7034167). Morphology consisted of small mature B-cells that were seen extensively infiltrating the bone marrow (Image 2). Flow cytometry revealed a clonal population of CD5negative/CD10-negative phenotype. Due to the morphologic nature and CD103 negativity, hairy cell leukemia was deemed less likely. Given the lack of an identifiable M-component on serum protein electrophoresis and the splenomegaly present, lymphoplasmacytic lymphoma was also unlikely. Cytogenetic evaluation revealed the loss of $7 \mathrm{q}$ and a gain of chromosome 3 (3 copies of 3 q27 BCL6 probe) which is observed in marginal zone lymphoma. On imaging, no intrathoracic, intra-abdominal, retroperitoneal, or pelvic lymph nodes were present. All features above were suggestive of splenic marginal zone lymphoma and treatment was planned.

She was initiated on IV rituximab $375 \mathrm{mg} / \mathrm{m}^{2}$ (day 1/28) with bendamustine $90 \mathrm{mg} / \mathrm{m}^{2}$ (days 2-3/28) regimen (BR) every twenty-eight days for six cycles. Considering her hepatitis B surface antigen positivity, tenofovir was given prophylactically, although hepatitis B DNA quantitative evaluation was negative with $<10 \mathrm{IU} / \mathrm{mL}$.

She tolerated treatment well. After cycle \#2, her pancytopenia improved. She was able to flex and extend her toes and knees without improvement in her hip flexors or extensors. After cycle \#3, her fatigue and night sweats started to improve and she was able to stand shortly without assistance. She continued to work with physical therapy and at the completion of final sixth cycle of BR, she was able to stand up without assistance and ambulate on her own, nearly six months after her initial presentation.

Repeat bone marrow biopsy done approximately three weeks after her last cycle showed no immunophenotypic evidence of a mature B-lymphoid neoplasm and normal flow cytometry. Complete imaging done three months after therapy showed significant reduction in splenic size from $26 \mathrm{~cm}$ to $16 \mathrm{~cm}$ with no adenopathy noted. Further surveillance continued to show splenic size reduction to $14 \mathrm{~cm}$.

24 months after diagnosis, the patient continues to enjoy life at home, fully ambulatory and disease-free.

\section{Discussion}

The morphology of SMZL is characterized by an infiltrate of centrocyte-like small cleaved cells, monocytoid B-cells or small lymphocytes with a round nucleus, condensed chromatin, and abundant basophilic cytoplasm with small surface "villous" projections [13]. Splenic hilar lymph nodes are commonly involved, though marginal zone pattern is variable [14]. Bone marrow involvement can be subtle with lymphoid aggregates, variable marginal zone pattern and intrasinusoidal lymphoid infiltration [15]. About 20-25\% of patients may be observed to have no cytopenias or symptomatology [16].

There are previously reported causes of neurologic symptomatology including Guillain-Barré syndrome and sarcoidosis in SMZL. Our patient was evaluated for such phenomenon and workup was negative. She was treated empirically with plasmapheresis without improvement. Although there has been a radiographic report published in the literature so far, no clinical documentation of paraneoplastic paraplegia in SMZL has been reported [17]. Moreover, complete resolution of paraplegia after treatment of the underlying SMZL has not been reported.

Being a systemic disease with significant morbidity and mortality, splenectomy alone is being questioned as first-line therapy, with systemic therapy being accepted as the mainstay of treatment. This case exhibits a case of SMZL, accompanied by a rare phenomenon of a paraneoplastic paraplegia which resolved completely with treatment of the lymphoma.

\section{Conclusion}

Splenic marginal zone lymphoma (SMZL) is a rare disease, classified as a mature B-cell indolent lymphoma, accounting for less than one percent of all NHLs. Being a rare disease presenting as an atypical phenomenon of paraplegia, this patient improved with treatment and achieved complete response of disease and paraplegia. This is the first known case of such a rare entity clinically described.

\section{Competing Interests}

The authors declare that they have no competing interests.

\section{References}

[1] C. Thieblemont, "Clinical presentation and management of marginal zone lymphomas," Hematology/The Education Program of the American Society of Hematology, pp. 307-313, 2005.

[2] L. Liu, H. Wang, Y. Chen, L. Rustveld, G. Liu, and X. L. Du, "Splenic marginal zone lymphoma: a population-based study on the 2001-2008 incidence and survival in the United States," Leukemia and Lymphoma, vol. 54, no. 7, pp. 1380-1386, 2013. 
[3] G. Delsol, J. Diebold, P. G. Isaacson et al., "Pathology of the spleen: report on the workshop of the VIIIth meeting of the European Association for Haematopathology, Paris 1996," Histopathology, vol. 32, no. 2, pp. 172-179, 1998.

[4] E. Matutes, R. Morilla, K. Owusu-Ankomah, A. Houlihan, and D. Catovsky, "The immunophenotype of splenic lymphoma with villous lymphocytes and its relevance to the differential diagnosis with other B-cell disorders," Blood, vol. 83, no. 6, pp. 1558-1562, 1994.

[5] E. Matutes, D. Oscier, C. Montalban et al., "Splenic marginal zone lymphoma proposals for a revision of diagnostic, staging and therapeutic criteria," Leukemia, vol. 22, no. 3, pp. 487-495, 2008.

[6] C. Thieblemont, P. Felman, F. Berger et al., "Treatment of splenic marginal zone B-cell lymphoma: an analysis of 81 patients," Clinical Lymphoma, vol. 3, no. 1, pp. 41-47, 2002.

[7] R. Milosevic, M. Todorovic, B. Balint et al., "Splenectomy with chemotherapy vs surgery alone as initial treatment for splenic marginal zone lymphoma," World Journal of Gastroenterology, vol. 15, no. 32, pp. 4009-4015, 2009.

[8] C. Kalpadakis, G. A. Pangalis, T. P. Vassilakopoulos, S. Sachanas, and M. K. Angelopoulou, "Treatment of splenic marginal zone lymphoma: should splenectomy be abandoned?" Leukemia and Lymphoma, vol. 55, no. 7, pp. 1463-1470, 2014.

[9] A. M. Tsimberidou, D. Catovsky, E. Schlette et al., "Outcomes in patients with splenic marginal zone lymphoma and marginal zone lymphoma treated with rituximab with or without chemotherapy or chemotherapy alone," Cancer, vol. 107, no. 1, pp. 125-135, 2006

[10] M. Bennett, K. Sharma, S. Yegena, I. Gavish, H. P. Dave, and G. P. Schechter, "Rituximab monotherapy for splenic marginal zone lymphoma," Haematologica, vol. 90, no. 6, pp. 856-858, 2005.

[11] C. Kalpadakis, G. A. Pangalis, M. N. Dimopoulou et al., "Rituximab monotherapy is highly effective in splenic marginal zone lymphoma," Hematological Oncology, vol. 25, no. 3, pp. 127-131, 2007.

[12] M. Else, A. Marín-Niebla, F. de la Cruz et al., "Rituximab, used alone or in combination, is superior to other treatment modalities in splenic marginal zone lymphoma," British Journal of Haematology, vol. 159, no. 3, pp. 322-328, 2012.

[13] M. J. Rummel, N. Niederle, G. Maschmeyer et al., "Bendamustine plus rituximab versus $\mathrm{CHOP}$ plus rituximab as first-line treatment for patients with indolent and mantle-cell lymphomas: an open-label, multicentre, randomised, phase 3 non-inferiority trial," The Lancet, vol. 381, no. 9873, pp. 12031210, 2013.

[14] E. Iannitto, A. Ambrosetti, E. Ammatuna et al., "Splenic marginal zone lymphoma with or without villous lymphocytes: hematologic findings and outcomes in a series of 57 patients," Cancer, vol. 101, no. 9, pp. 2050-2057, 2004.

[15] M. Mollejo, E. Lloret, J. Menárguez, M. A. Piris, and P. G. Isaacson, "Lymph node involvement by splenic marginal zone lymphoma: morphological and immunohistochemical features," American Journal of Surgical Pathology, vol. 21, no. 7, pp. 772-780, 1997.

[16] J. Audouin, A. Le Tourneau, T. Molina et al., "Patterns of bone marrow involvement in 58 patients presenting primary splenic marginal zone lymphoma with or without circulating villous lymphocytes," British Journal of Haematology, vol. 122, no. 3, pp. 404-412, 2003.
[17] D. W. Anderson and A. Borsaru, "Case report: lymphomarelated resolving paraneoplastic myelopathy with MRI correlation," The British Journal of Radiology, vol. 81, no. 964, pp. e103e105, 2008. 


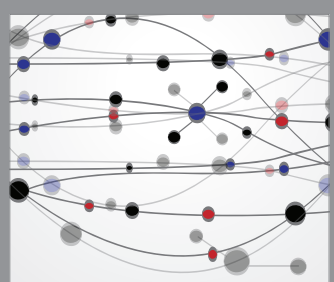

The Scientific World Journal
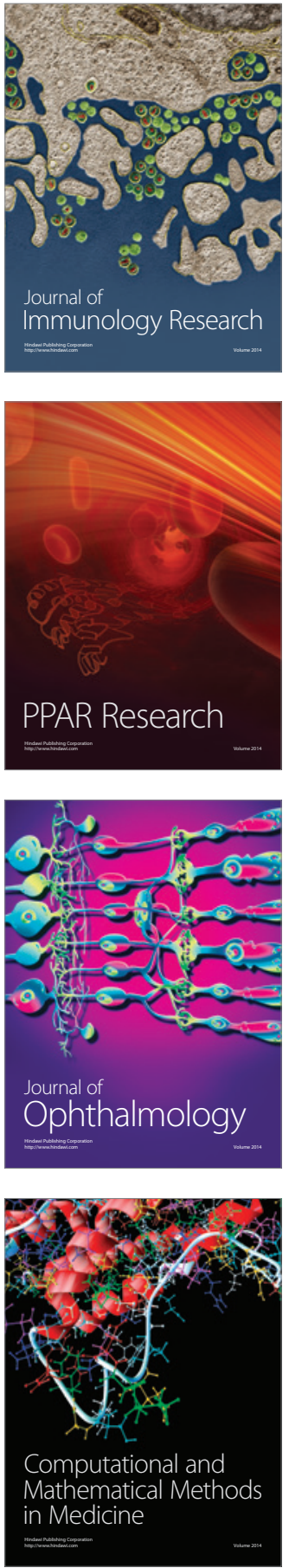

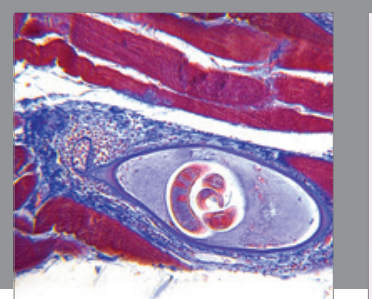

Gastroenterology Research and Practice

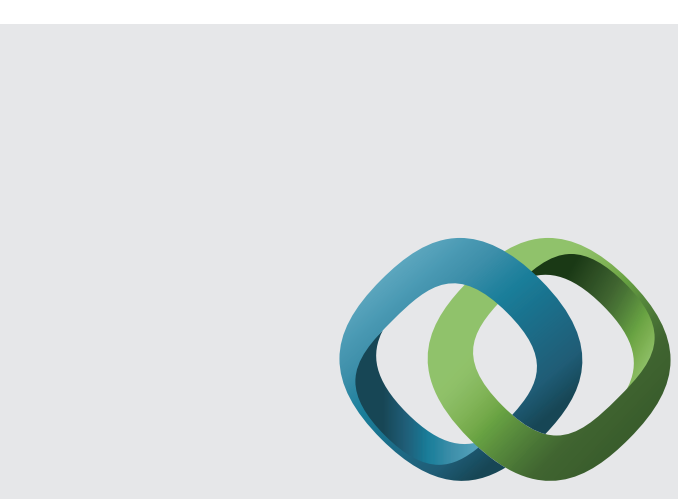

\section{Hindawi}

Submit your manuscripts at

http://www.hindawi.com
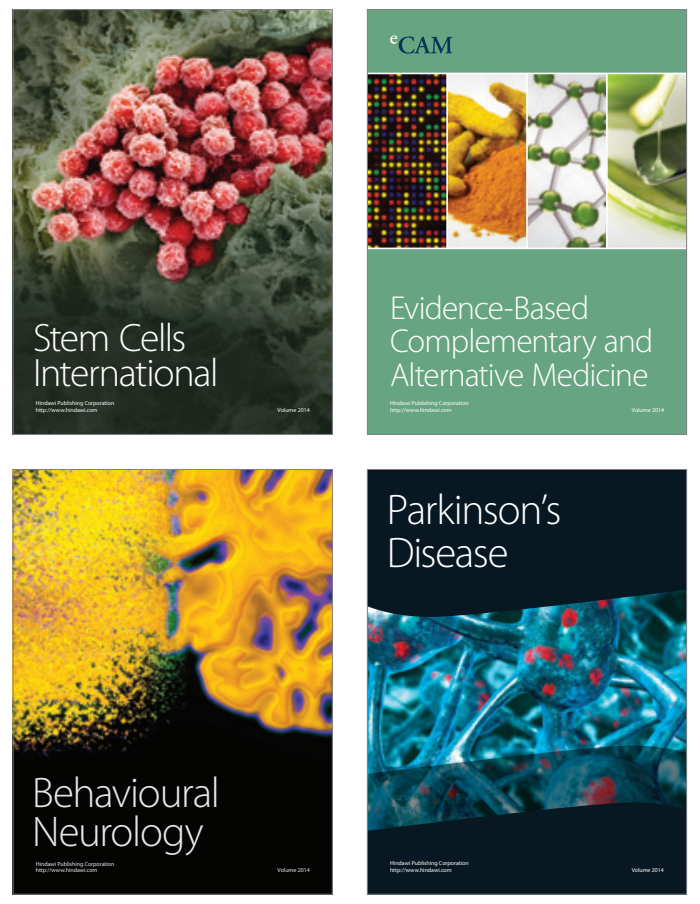
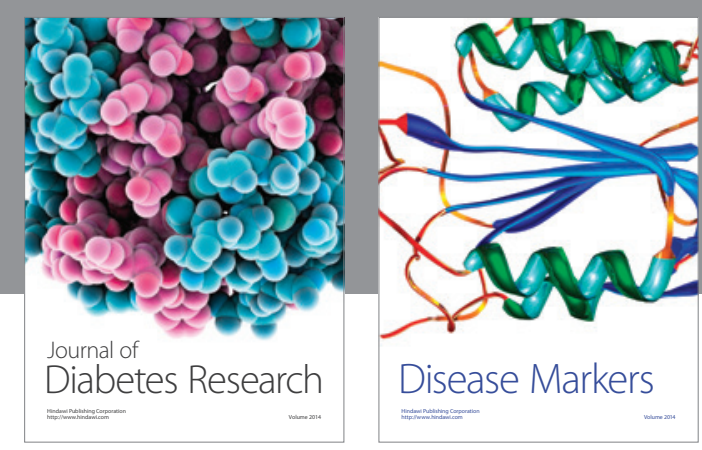

Disease Markers
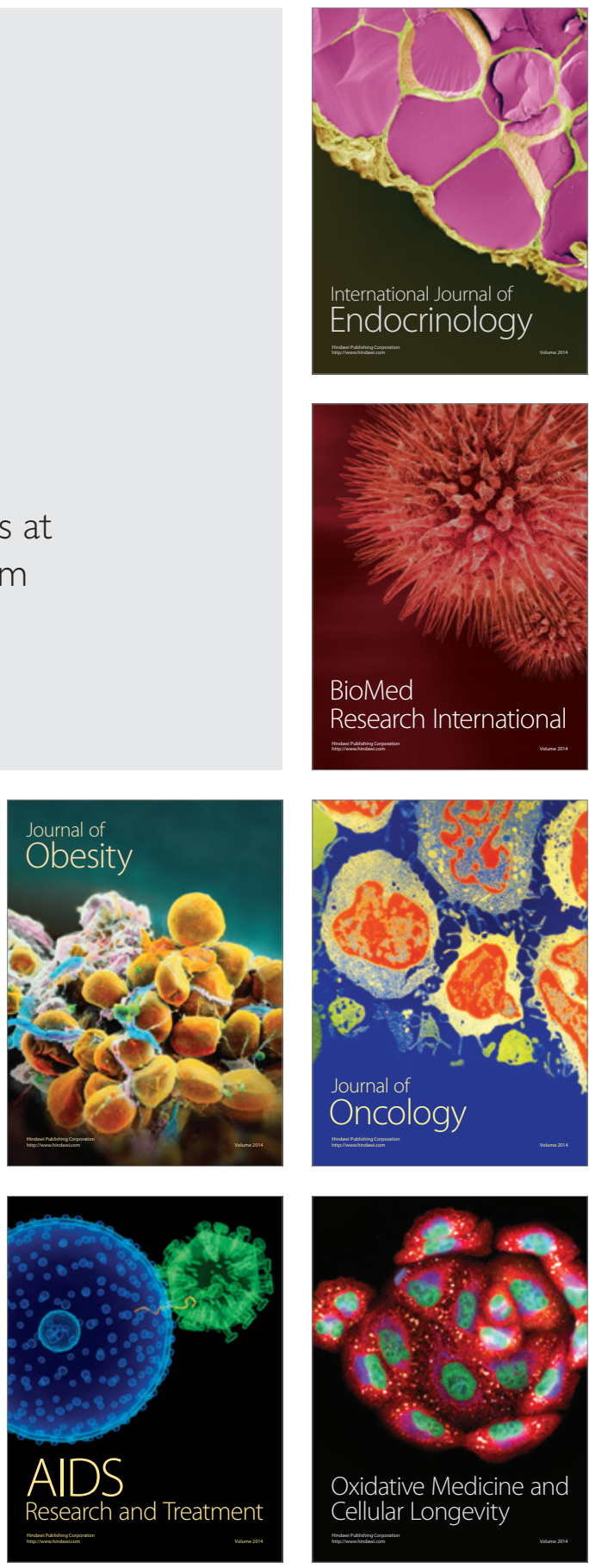